\title{
DRIVERS OF ADOPTION INTENSITY OF IMPROVED AGRICULTURAL TECHNOLOGIES AMONG RICE FARMERS: EVIDENCE FROM NORTHERN GHANA
}

\author{
Joseph Agebase AWUNI, Shaibu Baanni AZUMAH *, Samuel Arkoh DONKOH
}

\author{
Address: \\ University for Development Studies, Faculty of Agribusiness and Communication Sciences, Department of Agriculture \\ and Resource Economics, P. O. Box TL 1350. Tamale, Ghana. \\ * Corresponding author e-mail: : raszumah1983@gmail.com, sazumah@uds.edu.gh
}

\begin{abstract}
Improved rice production techniques are being promoted in Ghana as a way of enhancing sustainable productivity among farmers. Despite the important role that the adoption of improved rice production technologies plays in improving output, very few studies, especially in the context of Northern Ghana, have been conducted to analyse the factors influencing their intensive adoption. In this study, we compared the results of negative binomial, Poisson and zero inflated Poisson (ZIP) models to analyse the determinants of intensity of adoption of improved rice production techniques, using primary data collected from 543 rice farmers in the Upper East and Northern regions of Ghana. Based on model diagnostics, we accept the results of the ZIP model. The empirical results confirm the relevance of technology demonstration fields, farmers' experience, training, and sex of the farmer in enhancing and sustaining the adoption of improved agricultural technologies. Household extension method, research and extension, and farm size should also be considered in promoting the adoption of improved practices among rice farmers since these covariates had significant relationship with the intensity of adopting improved agricultural technologies.
\end{abstract}

Keywords: Adoption intensity, Agricultural technologies, Rice, Zero Inflated Poisson model, Northern Ghana JEL: R52, R58, H41

\section{INTRODUCTION}

The Food and Agricultural Organisation FAO (2013) estimates that food production must increase by at least 60 percent to respond to the demand of the 9 billion people that are expected to inhabit the planet by 2050 . Given that one in eight people are currently food insecure, ensuring global food security over the next decades will be essential. In meeting this challenge, there is an opportunity to create sustainable economic growth in rural areas of developing countries where food security and poverty are most prevalent. It has been predicted that over the next few decades, billions of people, especially those living in developing countries like Ghana, will face shortages of water and food and greater risks to health and life because of climate change. With fewer socio-technological and financial resources for adapting to the changing conditions, developing countries are the most vulnerable to the impacts of climate change (UNFCCC, 2007). The critical role of the agricultural sector in most African economies can therefore not be overemphasised.

Aside providing food and raw materials, the agricultural sector plays a critical role of employment for many, especially the rural folks. In Ghana for instance, the agricultural sector alone employs up to about $44.7 \%$ of the total labour force, majority of whom live in rural Northern Ghana (GLSS, 2014), and contributes about 20\% Ghana's current GDP despite a drastic decline in the past few decades. However, smallholder farmers in the Northern and Upper East regions of Ghana continue to contribute significantly to Ghana's cereal stock (rice inclusive) (MoFA, 2016).

Rice production in Ghana has increased significantly over the past decades. For instance, the Statistics, Research and Information Directorate (SRID) of Ministry of Food and Agriculture (MoFA, 2013) reported that the land area under the cultivation of rice increased from 123 , $000 \mathrm{Ha}$ in 2002 to about 189, $000 \mathrm{Ha}$ in 2012. However, average yield per hectare is still 2.5 as against the achievable yield of $6.5 \mathrm{MT} / \mathrm{Ha}$ (MoFA, 2013; 2016). Until 2008, the total output of paddy rice for Ghana was below 300, 000 MT. However, local production has increased from 391, $000 \mathrm{MT}$ in 2009 to 641, $000 \mathrm{MT}$ in 2015 (MoFA, 2013; 2016).

The expansion in the production of rice is largely attributable to the expansion in area under cultivation. However, favourable rain patterns, the national fertilizer subsidy programme and the block farm programme have contributed to the increase in the national rice output (Ragasa et al., 2013).

Although rice is produced in all the ten regions of Ghana, Northern, Upper East and Volta regions are mainly responsible for the majority of rice produced in the country. Average yield of $2.96 \mathrm{MT} / \mathrm{Ha}$ in these three regions exceeds the national average of $2.5 \mathrm{MT} / \mathrm{Ha}$ but is significantly lower than the average yield of $5.48 \mathrm{MT} / \mathrm{Ha}$ in the Greater Accra Region (MoFA SRID, 2016), suggesting that the adoption of the right technologies could enhance yields and output (Angelucci et al., 2013). 
Subsequently, some projects in northern Ghana such as the Rice Sector Support Project (RSSP), the IFDC led Feed the Future USAID-Ghana Agriculture Technology Transfer Project, the Quality Rice Development project, ADVANCE II project among others, have promoted some improved rice production practices such as bunding, proper spacing, irrigation, harrowing/rotovation and row planting. These practices or technologies have been proven to contribute to yield improvements through experimentations by these projects, and therefore farmers are being encouraged to adopt them.

While proper spacing at $20 \mathrm{~cm} \times 20 \mathrm{~cm}$ improves plant population and enhances easy farm management, bunding is said to improve water retention in an irrigated or watered space. Harrowing or rotovation in rice production loosens and levels the soil for adequate water spread across the farm, and also allows for good penetration of water and nutrients at the early stages of the rice plant. Row planting or transplanting also improves plant population, and also allows for easy weeding to maintain farm hygiene.

Despite the fact that a lot of studies have been conducted on improved agricultural technology adoption in developing countries' context (for example, Azumah, Donkoh, and Ansah, 2017; Danso-Abbeam, and Baiyegunhi, 2017; and Abdul-Hanan, Ayamga, and Donkoh, 2014), only a few account for intensity of adoption (Nkegbe and Shankar, 2014). While the decision to adopt is usually said to have binary outcome (i.e. to adopt or not to adopt), intensity of adoption goes further to look at the extent to which the various techniques are adopted. In analysing the adoption decisions of improved rice production technologies, count data models are employed in which the number of practices adopted serves as a measure of intensity of adoption (see, for example, Nkegbe \& Shankar, 2014; Sharma et al., 2011).

The objective of this study was therefore, to identify the determinants of multiple rice production technologies adoption by rice farmers in Northern Ghana (particularly, the Northern and Upper East regions). Previous studies mentioned above account for overdispersion, where the variance of the count-dependent variable is greater than the conditional mean. The current study is somewhat unique in the sense that it accounts for excess zeros in analysing the intensity of adoption of improved rice production techniques by rice farmers in Northern Ghana, and also compares the estimates of negative binomial, Poisson, and zero inflated Poisson models. In the presence of under-dispersion, both overdispersion and equidispersion models (negative binomial and normal Poisson) will result in unreliable estimates.

This paper is contains five main sections. The introductory section above provides background to the study. The rest of the paper is structured as: Data and Methods, which captures the study area, sampling, and data collection methods, analytical framework, as well as description of variables; Results and Discussions, which looks at the drivers of adoption intensity of improved rice production technologies; and conclusions with policy implications.

\section{DATA AND METHODS}

\section{Study area, sampling, data collection methods}

The study was conducted in Ghana, using primary data from rice farmers in the Northern and Upper East region. The Upper East Region of Ghana is located in the northeastern corner of the country and bordered by Burkina Faso to the north and Togo to the east and to the west by Sissala east and west districts in Upper West region and the south by West Mamprusi district in the Northern Region. The land is relatively flat with a few hills to the East and south-eastern parts. The total land area of the upper east region is about $8,842 \mathrm{sq}$. $\mathrm{km}$, which translates into $2.7 \%$ of the total land area of Ghana. The Northern Region is the largest of the 10 regions of the country in terms of landmass, occupying 70,384 square kilometres and accounting for $29.5 \%$ of the total land area of Ghana. It shares boundaries with the Upper East and the Upper West Regions to the north, the Brong Ahafo and the Volta Regions to the south, and two neighbouring countries, the Republic of Togo to the east, and Cote d' Ivoire to the west.

These two regions are the second (Northern region) and third (Upper East region) largest producers of paddy rice in Ghana, producing up to about 290,000 metric tons of paddy on annually but with very low average yield compared to national figures (MoFA SRID, 2016). The two regions have also been identified among the poorest in Ghana, with poverty levels of about $50 \%$ and $44 \%$ in the Northern and Upper East region respectively (GSS, 2014). Basically, two climatic conditions pertain in the northern part of Ghana. The rainy season which begins lightly in April and rises steadily to a peak in August/September and gradually decline by October/November. There is also a dry season which occurs between November and April with a peak in February and also characterized by dry harmattan winds which engulf the whole sub region. The vegetation of the area is generally the Guinea savannah with its characteristic grass and trees. The biodiversity in tree vegetation used to be high, but now it is decreasing due to over exploitation. The major economic activity of the people is agriculture. Presently, the agricultural sector employs the largest share of the economically active population the Northern and Upper East regions of Ghana. While about $70 \%$ of the estimated economically active rural population in the Northern region are employed by the agriculture sector, the case for the Upper East region is about 79\% (MoFA SRID, 2016). These values are far above the national average of $41.2 \%$ (GSS, 2012). Among the several crops grown in the region are maize, millet, rice, yam, sorghum, groundnut, cowpea and Bambara groundnuts. The traditional hoe is the most important farm tool, but those who can afford, do use bullocks and tractor ploughing service for land preparation. The regions also have a high potential in animal production in Ghana (MoFA, 2016). The most predominant animals found in the area include cattle, sheep, goat, guinea fowls, fowls, and donkeys. While the crops are mainly grown for subsistence, the animals are mainly for cash and are mostly kept as an insurance or in-kind savings for the family. 
Rice farmers in the Guinea Savannah ecological zone of the Northern and Upper East region constituted the population $(\mathrm{N})$ for this study. Rice farmers of the major irrigation schemes as well as those located in areas of vast natural rice valleys were considered. The Ghana Living Standard Survey (GLSS) round 6 (GSS, 2014) puts the number of households in the Guinea Savannah zone who produce rice at 296,489. Multistage sampling method was adopted to select the respondents. In the first stage, the two northern regions were purposively selected based on their high nominal contribution to the rice sector of Ghana, and also because productivity for rice is lowest in these regions (MoFA, 2013; 2016). Again, the regions have the dominant vast natural lowland suitable for rice production and also have irrigations schemes that have produced rice over the years. Stratified sampling method was used to group the farmers into rain fed and irrigation farmers in the two regions. All five (5) irrigations schemes in the two regions were considered for this study (i.e. Tono and Vea in the Upper East region, Libga, Golinga and Bontanga in the Northern region). Simple random sampling technique was then used to select 600 farmers from the two strata (i.e. irrigation and rain fed ecologies) spread across 62 selected communities in 10 districts (Builsa north, Kassena-Nankana West, Kassena-Nankana East, Bongo and Bolgatanga for the Upper East region, and Karaga, Gushegu, Tolon, Kumbungu, Central Gonja, and Savelugu-Nantong districts for the Northern region) of the Upper East and Northern regions. However, 543 out of the 600 questionnaires contained all the data needed for the purpose of analyses. A questionnaire was designed to collect primary data from rice farmers. This comprised of socio-economic and demographic information as well as technology application and adoption characteristics of the farmers.

\section{Analytical framework - the Zero Inflated Poisson (ZIP) model}

In principle, technology adoption or selection can be modelled using a multinomial logit or probit specification, where the dependent variable is a categorical. But count data model can also be used to model technology selection, where the dependent variable is the sum of the number of improved agricultural technologies selected. Count data models do offer some useful advantages for technology adoption studies. Count data models focus on adoption intensity.

The existing count data literature on technology adoption typically employs parametric specifications such as the Poisson model or the Negative Binomial regression. The number of technologies adopted (in this case, improved rice production technologies) is the dependent variable and a set of farm level and socio-economic characteristics are explanatory variables. For example, Abdul-Hanan, Ayamga and Donkoh (2014), Sharma $e t$ al. (2011), Isgin et al. (2008), and Lohr and Park (2002), employed count data models to examine technology adoption. Lohr and Park (2002) rejected the Poisson model in favour of the Negative Binomial. Isgin et al. (2008) employed Poisson and Negative Binomial specifications. Sharma et al. (2011) employed both parametric (OLS, Poisson and Negative Binomial specifications) and non-parametric methods to assess the determinants of technology adoption.

Overall, Sharma et al. (2011), as in the case of this present study, find that there is a reasonable degree of agreement between the results generated by the various methods. Sharma et al. (2011) selected the Negative Binomial specification over the Poisson and OLS specifications from the parametric method and, although not overwhelmingly so, their preferred set of results was generated by the nonparametric method employed. While our tests result supported the use of zero inflated poison model (ZIP), we estimated also, the negative binomial and Poisson regression models for comparison.

A zero-inflated model is a statistical model based on a zero-inflated probability distribution, i.e. a distribution that allows for frequent zero-valued observations. In other words, the ZIP regression is used to model count data that has a lot of zero counts (Cameron, and Trivedi, 2010). The first zero-inflated model is the zero-inflated Poisson model, which concerns a random event containing excess zero-count data in unit time (Lambert, 1992). For example, the number of improved agricultural technologies adopted by rice farmers would be zeroinflated by those farmers who have not adopted any of the identified improved technologies.

Further, theory suggests that the excess zeros are generated by a separate process from the count values and that the excess zeros can be modelled independently. Thus, the ZIP model has two parts, a Poisson count model (see Table 3) and the logit model for predicting excess zeros (see Table 4). The two model components are described by Eq. $1-2$.

$$
\begin{aligned}
& P_{r}=\left(y_{i}=0\right)=\pi+(1-\pi) e^{-\lambda} \\
& P_{r}\left(y_{i}=h_{i}\right)=(1=\pi) \frac{\lambda^{h_{i}} e^{-\lambda}}{h_{i} !}, h_{i}>1
\end{aligned}
$$

Where the outcome variable $y_{i}$ has any non-negative integer value, $h_{i}$ is the expected Poisson count for the $i^{\text {th }}$ individual; $\pi$ is the probability of extra zeros. The mean is $(1-\pi) \lambda$ and the variance is $\lambda(1-\pi)(1+\pi \lambda)$. The methods of moments estimators are given by Eq. 3 .

$$
\begin{aligned}
& \lambda_{m o}=\frac{s^{2}+m^{2}}{m}-1, \\
& \pi_{m o}=\frac{s^{2}-m}{s^{2}+m^{2}-m}
\end{aligned}
$$

Where $m$ is the sample mean and $s^{2}$ is the sample variance. The maximum likelihood estimator (Johnson, Kotz, Kemp, 1992) can be found by solving the Eq. 5 .

$X\left(1-e^{-\lambda_{m l}}\right)=\lambda_{m l}\left(1-\frac{n_{o}}{n}\right)$

Where $X$ is the sample mean, and $\frac{n_{0}}{n}$ is the observed proportion of zeros.

This can be solved by iteration (Böhning et al., 1999), and the maximum likelihood estimator for $\pi$ is given by Eq. 6 . 
$\pi_{m l}=1-\frac{X}{\lambda_{m l}}$

Where the variables are as defined.

\section{Description of variables}

Table 1 provides a summary of definitions for 17 variables used in this study. While $42 \%$ of the farmers had access to information on improved technologies via the household extension method, about $73 \%$ also had information through attending technology demonstration field days. Only $29 \%$ of the farmers had access to Television sets which could assist them in learning improved farming techniques. A small percentage of farmers also had access to information via video $(36 \%)$. However, majority of the farmers (72\% and 63\%) had information on improved production technologies via radio and also through their mobile phones respectively.

About $68 \%$ of the respondents were from the Northern region. The rest of the $32 \%$ of the respondents were from the Upper East region of Ghana. The proportion of the sample assigned to each region was based on the density of rice production points in the two regions, with the northern region being dominant in the production of the commodity.

The average age of a rice farmer in the study area is 38.51 years (Table 1). Azumah et al. (2017) also found the average age of farmers in the northern region of Ghana to be 39.7 years. These indicate a relatively youthful age for rice farmers in the study area since MoFA (2013) reported the average age of farmers to be 55 years in Ghana. The finding is good for agricultural development in Northern Ghana considering that agricultural activities around the area involves much labour as mechanisation is still a challenge.

Male farmers (83\%) were found to be dominant in the cultivation of rice. This finding does not however suggest that females were least involved in rice production, focus group discussions conducted with female and male rice farmers in the two regions revealed that the activities in rice production appeared led by the males because they owned the lands on which production activities are carried out. In most cases, the females provided labour for transplanting/direct seeding, weeding and harvesting alongside the male farmers. Also, females are mostly responsible for value addition such as parboiling and processing of rice for onward sale in local markets.

On the average, a farmer had up to only 4.05 years of formal education. This finding indicates a low level of formal education among farm workers in the northern part of Ghana. While the national average for the population of 15 years who had ever attended school in Ghana currently stands at $85.3 \%$, the regional figures for the Northern and Upper East regions of Ghana are $55.7 \%$ and $59.4 \%$ respectively, placing the two regions as the worst performing regions when it comes to formal education in Ghana (GSS, 2014). The results also revealed that rice farmers in the study area were very experienced as the average farmer possessed more than a decade of knowledge in rice production. The result from Table 1 also revealed that $64 \%$ of the farmers were members of farmer groups, which was positive as the farmers strive to formalize their operations.

Only $55 \%$ of the farmers had access to extension and research service the previous season. The poor agricultural extension system in Ghana could be attributed to the low investment by the government in the agriculture sector lately. Graduates from the agriculture training colleges and universities in Ghana are no more automatically recruited into MoFA to provide extension services to farmers like it used to be in the 1980s and 1990s. This has widened the agriculture extension agent farmer ratio to about 1:3000 (GSS, 2014), leaving the NGO area to fill the gap by providing training on improved technologies to farmers. However, the uncoordinated manner in which the NGOs deliver services to the farmers culminate into transmitting several conflicting information to the same farmers depending on the individual interest of these NGOs.

Just about $12 \%$ of the farmers had access to production credit in the previous season. This is an indication of low level of financing for agricultural activities in the area. Climate change is now evident in the area, making investments into the agricultural sector riskier than ever, a possible justification by financial institutions to shy away from funding production activities of rice farmers in the area. A high percentage of farmers $(72 \%)$ had received training on improved agricultural technologies for rice production the previous season, which could be attributed to the many donor-led agricultural and development interventions in the study area.

The average household size was found to be 9.35 , indicating that household sizes in the study area were relatively high compared with Ghana's national average of 4.0 (GSS, 2014). We also found the average land holding per rice farmer in the study area to be 2.42 acres (translating into 0.96 hectares). This indicates that the average land holding for rice production was low in the area. Generally, average farm sizes for crop production is supposed to reduce with Ghana's current increasing trend in population growth. On an average, a farmer adopted 3.5 technologies.

\section{RESULTS AND DISCUSSION}

\section{Determinants of rice farmers' decision for joint adoption of improved agricultural technologies (adoption intensity)}

Before proceeding with the discussions on adoption of improved agricultural technologies by the farmers, we first present a breakdown of joint adoption levels of the farmers for the various technologies (i.e. nursery establishment, harrowing, line planting, proper spacing, urea briquette, irrigation, and bunding) (See Table 2). In Table 3 also, we present the frequency of adoption for each technology.

The results from Table 2 reveal that about $13 \%$ of the sampled farmers did not adopt any of the improved technologies and thus have a zero count. While $10.5 \%$ of the respondents adopted only one technology, the majority adopted two technologies, constituting $16.94 \%$ of the respondents. 
Table 1: Definition of variables and descriptive statistics

\begin{tabular}{|c|c|c|c|}
\hline Variable & Definition & Mean & SD \\
\hline Region & Dummy: 1 for a farmer in northern region, 0 for a farmer in upper east region & 0.68 & 0.47 \\
\hline $\begin{array}{l}\text { HH. Ext } \\
\text { method }\end{array}$ & $\begin{array}{l}\text { Dummy: } 1 \text { for a farmer who accessed information via } \mathrm{HH} \text { extension method, } 0 \text { if } \\
\text { otherwise }\end{array}$ & 0.42 & 0.49 \\
\hline Demos & $\begin{array}{l}\text { Dummy: } 1 \text { for a farmer who accessed information via farmer led field technology } \\
\text { demonstration method, } 0 \text { if otherwise }\end{array}$ & 0.73 & 0.45 \\
\hline TV & Dummy: 1 for a farmer who accessed information via TV, 0 if otherwise & 0.29 & 0.45 \\
\hline Radio & Dummy: 1 for a farmer who accessed information via radio, 0 if otherwise & 0.72 & 0.45 \\
\hline Video & Dummy: 1 for a farmer who accessed information via video, 0 if otherwise & 0.36 & 0.48 \\
\hline $\begin{array}{l}\text { Mobile } \\
\text { phone }\end{array}$ & $\begin{array}{l}\text { Dummy: } 1 \text { for a farmer who accessed information via mobile phone, } 0 \text { if } \\
\text { otherwise }\end{array}$ & 0.63 & 0.48 \\
\hline Education & Number of years spent in formal schooling. & 4.05 & 5.14 \\
\hline Experience & The total number of years a farmer has been cultivating rice. & 11.72 & 7.66 \\
\hline FBO & Dummy: 1 for if the farmer belongs to a farmer group, 0 if otherwise & 0.64 & 0.48 \\
\hline $\begin{array}{l}\text { Research \& } \\
\text { Ext }\end{array}$ & Dummy: 1 for access to research/extension staff in the last season, 0 if otherwise & 0.55 & 0.5 \\
\hline Training & Dummy: 1 if farmer had access to trainings last season, 0 if otherwise. & 0.71 & 0.45 \\
\hline $\begin{array}{l}\text { Credit } \\
\text { access }\end{array}$ & Dummy: 1 for access to credit in the last growing season, 0 if otherwise. & 0.12 & 0.32 \\
\hline Farm size & $\begin{array}{l}\text { Natural log of farm size (measured in the total hectares of land under rice } \\
\text { production) }\end{array}$ & 2.42 & 3.62 \\
\hline HH size & Total number of people in housing unit that feed from the same source & 9.35 & 6.23 \\
\hline Sex & Dummy: 1 for male, 0 if otherwise & 0.83 & 0.37 \\
\hline Age & The total number of years from birth of a farmer. & 38.51 & 10.67 \\
\hline $\begin{array}{l}\text { Adoption } \\
\text { Int. }\end{array}$ & Number of improved agricultural technologies adopted (from 1 to 7 ) & 3.52 & 2.35 \\
\hline
\end{tabular}

Source: Analysis of field data, 2017

Table 2: Intensity of practice of improved agricultural technologies

\begin{tabular}{ccc}
\hline No. improved technologies & Freq. & $\%$ \\
\hline 0 & 69 & 12.71 \\
1 & 57 & 10.50 \\
2 & 92 & 16.94 \\
3 & 72 & 13.26 \\
4 & 49 & 9.02 \\
5 & 42 & 7.73 \\
6 & 86 & 15.84 \\
7 & 76 & 14.00 \\
\hline Total & 543 & 100 \\
\hline Mean adoption & & 3.5 \\
Variance & & 5.5 \\
\hline
\end{tabular}

Source: Analysis of field data, 2017

Table 3: Improved agricultural technologies

\begin{tabular}{lcc}
\hline Improved technology* & $\begin{array}{c}\text { Freq. (No. of } \\
\text { farmers practicing) }\end{array}$ & $\%$ \\
\hline Nursery & 321 & 59.12 \\
Harrowing & 237 & 43.65 \\
Line planting & 281 & 51.75 \\
Spacing & 287 & 52.85 \\
Urea briquette & 189 & 34.81 \\
Irrigation & 223 & 41.07 \\
Bunding & 276 & 50.83 \\
\hline $\mathrm{N}=543$ & &
\end{tabular}

*Multiple responses

Source: Analysis of field data, 2017
Another $13.26 \%$ of the respondents adopted three out of the seven indented technologies. Only $9.02 \%$ and $7.73 \%$ adopted four and five technologies respectively. Another, $15.84 \%$ of the farmers also adopted six technologies. However, $14 \%$ of the farmers adopted all the seven technologies.

The results from Table 3 reveal that about $59 \%$ of the respondents practiced nursery. This was followed by proper spacing of rice plants (about 53\%) and line planting (about $52 \%$ ). Also, about $51 \%$ of the farmers adopted bunding. The technologies with adoption rates below the midpoint of $50 \%$ were harrowing, irrigation and urea briquette with adoption rates of $43.65 \%, 41.07 \%$, and $34.81 \%$ respectively. Parametric results of negative binomial (NB), Poisson regression and zero Inflated Poisson (ZIP) regression are provided in Table 4. Table 5 presents the parameter estimates of the logit (inflated) model for zero-inflated Poisson regression. We first tested for model specification to interpret results obtained from these models.

The ZIP model estimation is preferred to the Poisson and the NB models, and therefore was considered for further analysis and discussion. The estimated coefficient of alpha parameter $(\alpha=0)$ in the negative binomial model was significant, leading to a decisive rejection of the null hypothesis of equi-dispersion, suggesting the absence of over dispersion. Negative binomial regression is always safer to run than Poisson regression because even if the overdispersion parameter, alpha, in Stata is not statistically significant, the results will be exactly the same as its Poisson regression form (Cameron and Trivedi, 2010). This is confirmed by our results in Table 4 . 
Further tests for model selection revealed that the zero inflated Poisson model has marginally lower AIC (Akaike Information Criterion) and BIC (Bayesian Information Criterion) estimates compared to the NB and Poisson models. Table 4 shows there were many zeros, indicating a potential problem for NB and Poisson models as they do not capture excess zeros. Hence, we also tested the zero inflated model using the LR test of Vuong (1989) to identify a better model among the Poisson, NB and ZIP models. A large positive test value favours a ZIP model whereas a large negative value favours a Poison model (Cameron and Trivedi, 2010). In this study, the Vuong test statistics was 7.04, and significant at $1 \%$ level of significance, thereby favouring the ZIP model.

Out of the seventeen variables that were included in the ZIP model, seven were statistically significant in explaining the intensity of adoption of improved rice production technologies. Demonstration, experience, training and sex of the farmer positively influenced adoption intensity of improved technologies, while household extension method, research and extension, and farm size had negative relationship with the intensity of adopting improved technologies. All the media approaches/methods of technology transfer (i.e. TV, Radio, video, and mobile phone) were insignificant in explaining adoption intensity.

Household or individual extension method presents a number of advantages including the fact that unclear messages that have not been fully understood by the farmer can easily be clarified when using this method. Also, the extension officer is able to secure cooperation and inspire confidence in the family through personal contact. The results in Table 4 however show a significant and negative relationship between household extension method and the number of improved technologies adopted by farmers. Implying that, farmers who received information through the household extension method rather adopted less number of improved agricultural technologies for rice production. Anandajayasekeram et al. (2008) noted that this method was seldom used because of its high cost in terms of time and transport. Only a few farmers may actually be visited, providing justification for other methods such as the mass media and technology demonstration field days to be used.

Demonstration was significant and positively influenced rice farmers' adoption of more improved agricultural technologies, corroborating with Uzonna and Qijie (2013). This implies that farmers who attended field days where improved technologies were demonstrated adopted more improved rice production technologies than their counterparts who did not participate in any technology demonstration filed days. Anandajayasekeram et al. (2008), identified two kinds of demonstration, both having the same aim of improving technology diffusion and adoption. They noted that 'result demonstration' shows farmers the results of a practice that has been in use for some time. It is intended to arouse the farmers' interest in the practice. This can also be used to compare older practices or techniques with new ones. 'Method demonstrations' on the other hand, show farmers how a particular activity or task is carried out. It is effective in teaching since farmers can practice, see, hear, and discuss during the demonstration (Anandajayasekeram et al., 2008).

The positive relationship between experience and adoption intensity implies that long years of producing rice (modelled in this study as experience) results in farmers adopting more improved technologies to improve the output of rice in the long run. As farmers continue to produce, they learn new techniques, and are supposed to change or adapt to these new techniques as they progress on the learning curve. This result conforms to our a priori expectation and corroborated by the finding of Azumah, Donkoh, and Ansah (2017), who found a positive correlation between experience and adoption intensity.

Contrary to our a priori expectation, we found the research and extension variable to have a negative but significant relationship with the adoption intensity, suggesting that exposing farmers to agricultural research and extension agents could actually reduce the adoption of more improved rice production technologies. This result contradicts the findings of Mensah-Bonsu et al. (2017), Danso-Abbeam and Baiyegunhi (2017), and Nkegbe and Shankar (2014), who found the extension variable significantly and positively influence the adoption of more improved production technologies by farmers. Perhaps, the influence of the NGO sector in providing technical and extension services to farmers in the study area is reducing the effect of the public research and extension system. DeGraft-Johnson et al. (2014), suggest that, for technologies that require some level of technical knowhow, having direct contact with extension services and projects increases the acquisition of relevant knowledge. Thus, if the high extension agent - farmer ratio can be reduced, the adoption of technologies will be enhanced. Ghana's growth and poverty-reduction strategy for 2006 to 2009 did seek to intensify these linkages, but a major challenge remains the low extension agent farmer ratio, which was at 1:1400 by the end of 2004 (NDPC, 2005), about 1:1500 in 2009 (NDPC, 2010), and bout 1:3000 presently (GSS, 2014), falling short of the 1:1200 target (Mensah-Bonsu et al., 2017).

In line with Azumah, Tindjina, Obanyi, and Wood (2017), training was positive and significantly related to the adoption of more improved agricultural technologies. The positive association implies that farmers who received more trainings were more inclined to adopting more of the improved agricultural technologies as compared with their counterparts who receive less trainings. Donkoh and Awuni (2011) in their study on the adoption of farm management practices in lowland rice production in northern Ghana, argued that training is an added input which embraces good performance and adoption. They further stated that the benefits of training included acquiring new knowledge, skills or attitudes being transferred to farmers. Also, Adesina, and BaidooForson (1995), found that farmers' participation in onfarm tests, as well as the number of times farmers attended trainings, influenced significantly and positively, their adoption of new agricultural technologies and good farm practices. 
Table 4: Parameter estimates of the determinants of adoption intensity: comparing Negative binomial and Poisson regression

\begin{tabular}{|c|c|c|c|c|c|c|c|c|c|}
\hline \multirow[t]{2}{*}{ Variable } & \multicolumn{3}{|c|}{ Negative binomial } & \multicolumn{3}{|l|}{ Poisson } & \multicolumn{3}{|c|}{ Zero Inflate Poisson } \\
\hline & Coef. & Std. Err. & $\mathrm{dy} / \mathrm{dx}$ & Coef. & Std. Err. & $\mathrm{dy} / \mathrm{dx}$ & Coef. & Std. Err. & $\mathrm{dy} / \mathrm{dx}$ \\
\hline Region & $-0.363 * * *$ & 0.074 & -1.073 & $-0.3631 * * *$ & 0.074 & -1.073 & -0.047 & 0.076 & -0.17 \\
\hline HH. Ext method & $-0.372 * * *$ & 0.059 & -1.137 & $-0.3723 * * *$ & 0.059 & -1.137 & $-0.174 * * *$ & 0.06 & -0.61 \\
\hline Demos & $0.278 * * *$ & 0.074 & 0.821 & $0.2781 * * *$ & 0.074 & 0.821 & $0.310 * * *$ & 0.074 & 1.03 \\
\hline TV & $0.147 * *$ & 0.067 & 0.476 & $0.1470 * *$ & 0.067 & 0.476 & 0.037 & 0.068 & 0.13 \\
\hline Radio & $0.3221 * * *$ & 0.065 & 0.945 & $0.3221 * * *$ & 0.065 & 0.945 & 0.03 & 0.066 & 0.10 \\
\hline Video & 0.045 & 0.057 & 0.142 & 0.045 & 0.057 & 0.142 & 0.002 & 0.058 & 0.01 \\
\hline Mobile phone & $-0.1477 * *$ & 0.053 & -0.473 & $-0.1477 * *$ & 0.053 & -0.473 & -0.011 & 0.054 & -0.04 \\
\hline Education & 0.0051 & 0.005 & 0.016 & 0.0051 & 0.005 & 0.016 & 0.004 & 0.005 & 0.01 \\
\hline Experience & 0.0033 & 0.004 & 0.01 & 0.0033 & 0.004 & 0.01 & $0.006^{*}$ & 0.004 & 0.02 \\
\hline FBO & 0.0309 & 0.054 & 0.097 & 0.031 & 0.054 & 0.097 & -0.017 & 0.055 & -0.06 \\
\hline Research \& Ext & $-0.1390 * *$ & 0.063 & -0.439 & $-0.1390 * *$ & 0.063 & -0.439 & $-0.209 * * *$ & 0.062 & -0.75 \\
\hline Training & $0.3963 * * *$ & 0.078 & 1.15 & $0.3963 * * *$ & 0.078 & 1.15 & $0.445 * * *$ & 0.079 & 1.45 \\
\hline Credit access & -0.0469 & 0.082 & -0.145 & -0.0469 & 0.082 & -0.145 & 0.099 & 0.083 & 0.36 \\
\hline Farm size & $-0.0519 * * *$ & 0.013 & -0.163 & $-0.0519 * * *$ & 0.013 & -0.163 & $-0.050 * * *$ & 0.012 & 0.01 \\
\hline HH size & 0.0003 & 0.004 & 0.001 & 0.0003 & 0.004 & 0.001 & 0.002 & 0.004 & -0.18 \\
\hline Sex & $0.1715^{* *}$ & 0.071 & 0.509 & $0.1715 * *$ & 0.071 & 0.509 & $0.177 * *$ & 0.072 & 0.59 \\
\hline Age & $0.0044^{*}$ & 0.003 & 0.014 & $0.0044^{*}$ & 0.003 & 0.014 & 0.003 & 0.003 & 0.01 \\
\hline Const. & $0.5466^{* * *}$ & 0.146 & & $0.5466^{* * *}$ & 0.146 & & $0.661 * * *$ & 0.147 & \\
\hline alpha & 5.88E-08 & 0.000 & & & & & & & \\
\hline \multicolumn{4}{|c|}{$\operatorname{LR~chi}^{2}(17)=327.11 \mathrm{Prob}>\mathrm{chi}^{2}=0.0000$} & \multicolumn{3}{|c|}{$\operatorname{LR~} \operatorname{chi}^{2}(17)=412.63$ Prob $>\operatorname{chi}^{2}=0.0000$} & \multicolumn{3}{|c|}{ LR chi $^{2}(17)=248.34$ Prob $>$ chi $^{2}=0.0000$} \\
\hline \multicolumn{4}{|c|}{ Pseudo $\mathrm{R}^{2}=0.1333$} & \multicolumn{3}{|c|}{ Pseudo $\mathrm{R}^{2}=0.1625$} & \multicolumn{3}{|l|}{ Pseudo $\mathrm{R}^{2}=$} \\
\hline \multicolumn{4}{|c|}{ Log likelihood $=-1063.43$} & \multicolumn{3}{|c|}{ Log likelihood $=-1063.43$} & \multicolumn{3}{|c|}{ Log likelihood $=-977.14$} \\
\hline \multicolumn{4}{|c|}{$\mathrm{AIC}=2164.858$} & \multicolumn{3}{|c|}{$\mathrm{AIC}=2162.858$} & \multicolumn{3}{|c|}{$\mathrm{AIC}=2026.285$} \\
\hline \multicolumn{4}{|l|}{$\mathrm{BIC}=2246.503$} & \multicolumn{3}{|c|}{$\mathrm{BIC}=2240.206$} & \multicolumn{3}{|c|}{$\mathrm{BIC}=2180.981$} \\
\hline
\end{tabular}

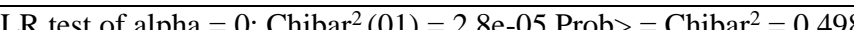

Vuong test of ZIP vs. Standard poison: $\mathrm{z}=7.04 \mathrm{Prob}>\mathrm{z}=0.000$

$*, * *$, and $* * *$ represent $10 \%, 5 \%$, and $1 \%$ level of significance respectively.

Source: Analysis of field data, 2017 
Table 5: Logit (inflated) model for zero-inflated Poisson regression

\begin{tabular}{lllr}
\hline Variable & Coef. & Std. Err. & dy/dx \\
\hline Region & $11.326^{* * *}$ & 3.3 & -0.17 \\
Ind. Ext method & $7.687^{* * *}$ & 2.9 & -0.61 \\
Demos & $-4.705^{* *}$ & 1.9 & 1.03 \\
TV & -25.551 & 17483.8 & 0.13 \\
Radio & $-12.175^{* * *}$ & 4.3 & 0.1 \\
Video & -3.273 & 2.5 & 0.01 \\
Mobile phone & $4.520^{*}$ & 2.5 & -0.04 \\
Education & $-0.167 *$ & 0.1 & 0.01 \\
Experience & 0.138 & 0.1 & 0.02 \\
FBO & $-11.486 * *$ & 4.6 & -0.06 \\
Research \& Ext & $3.921 *$ & 2.2 & -0.75 \\
Training & $-4.068^{* *}$ & 2 & 1.45 \\
Credit access & $5.624 * *$ & 2.6 & 0.36 \\
Farm size & 0.102 & 0.1 & 0.01 \\
HH size & $0.436 * * *$ & 0.1 & -0.18 \\
Sex & $3.657 *$ & 2.2 & 0.59 \\
Age & $-0.205^{* *}$ & 0.1 & 0.01 \\
Const. & -6.771 & 4.8 & \\
\hline
\end{tabular}

*,**, and *** represent $10 \%, 5 \%$, and $1 \%$ level of significance respectively

Another important result is the negative but significant association between farm size and adoption intensity of improved agricultural technologies. The negative association implies that, as the relative amount of land cultivated declines due to increasing population in the study area (GSS, 2014), farmers adopt more improved farm practices. It is likely also that, households with larger farm sizes could be labour constrained and so are not able to mobilise the required labour to apply improved production methods.

However, this point seems not to be in operation in the study area as the evidence suggests that household labour use on farm (proxied in this study as household size) was redundant in explaining the intensity of adoption of improved agricultural practices. This result corroborates with Mensah-Bonsu et al. (2017), and Nkegbe and Shankar (2014), who also found a negative and significant relationship between farm size and adoption intensity of land and water management practices among smallholder farmers in Northern Ghana. However, DansoAbbeam and Baiyegunhi (2017), Danso-Abbeam, Setsoafia, and Ansah (2014), and Sharma et al. (2011), have estimated that the total area farmed is positively related to the intensity of technology adopted.

Sex (gender) of the farmer was positive and significant also. This implies that male rice farmers in the study area had a higher probability of adopting more improved agricultural technologies than their counterpart female rice farmers. This finding conformed to our a priori expectation. The finding could be attributed to the socioeconomics and the socio-cultural orientations in the Northern part of Ghana where ownership of productive resources, especially agricultural land for rice production, is dominantly owned by men. These lands are mostly handed to male children as inheritance from their parents, with the explanation that female members of the household would be married out to other families in the future. The result of this study corroborates with AbdulHanan, Ayamga, and Donkoh (2014), who found that gender was positively related to the number of technologies adopted by farmers in their production efforts. They established that male farmers in Northern Ghana had a higher propensity to adopt more soil and water conservation techniques than females. They argued that adoption of these techniques were laborious and needed resources which typically are owned by men. Sadly, however, focus group discussions (FGDs) conducted with a number of farmer groups in the study area suggested that women, aside the tedious responsibility of housekeeping imposed on women by cultural and religious orders that pertain in the study area, were still responsible for a larger chunk of the labour demands on the various rice fields across the study area. Women are involved in activities across the entire production chain, including the value addition processes and marketing of the commodity, most of the time, on behalf of their households or husbands who have total ownership of the resources. The FGDs revealed that women were involved in the land preparation process, planting of rice (transplanting in most cases), harvesting, threshing, winnowing, bagging and carting of the rice to their homes. Women will usually perform the activities along size their male counterparts. According to Uzonna and Qijie (2013), women play an indispensable role in farming and improving the quality of life in rural areas, especially in Africa. FAO (2011), further asserted that, over $80 \%$ of women in developing countries provide 60 $80 \%$ of all agricultural labour, which appear to be the case in the study area.

As mentioned above, the Poisson and negative binomial models presented similar results (see Table 4). The significant covariates with negative relationship with the number of improved technologies adopted include the location (region) variable, household/individual extension method, mobile phone usage, research and extension, and farm size. The age of the farmer, sex (gender), attending trainings, access to radio, $\mathrm{TV}$, and technology demonstration fields were also significant and positive in both the negative binomial and Poisson regression models with similar coefficients.

The logistic part of the ZIP model had thirteen variables significantly explaining the adoption of improved technologies by rice farmers in the study area. Here, adoption intensity has binary outcome (i.e. 1 for adopters and 0 for non-adopters). Among the significant variables with positive association with adoption of improved agricultural technologies are location (region), household extension method, mobile phone access, access to research and extension, access to agriculture credit, household size and the sex (gender) of the farmer. This result implies that farmers located in the Northern region, those who had access to information through household extension method, those with access to mobile phones, research and extension, those who had access to farm credit and labour due to larger household sizes, as well as 
male farmers adopted one or more of the improved technologies.

On the contrary, farmers who had access to agricultural information through demonstration fields and radio, farmers with more formal education, older farmers who belonged to farmer based organisations (FBOs) and had access to trainings had lower probability of adopting one or more of the improved agricultural technologies.

\section{CONCLUSIONS}

Despite the gradual increases in the production trends of rice, Ghana remains a net importer as local consumption still outweighs production. Low productivity is still to blame for the huge deficit in the rice balance sheet of Ghana. The adoption of improved rice production technologies by rice farmers has become more necessary to address the issue of low productivity among rice farmers in Ghana. In this regard, some notable projects including the Rice Sector Support project (RSSP), the IFDC led Feed the Future USAID-Ghana Agriculture Technology Transfer Project, ADVANCE II project among others, have promoted some improved rice production practices such as bunding, proper spacing, irrigation, harrowing/rotovation and row planting in Northern Ghana. This study examined the drivers of adoption intensity of the promoted improved agricultural technologies for rice production using data from a cross section of 543 rice farmers in northern Ghana. We tested for the robustness of the estimates to arrive at the appropriate model specification for this study. In terms of methodology, there was uniform results across the Poisson and Negative binomial models. However, the Vuong test supported the use of the Zero Inflated Poisson model demonstrating the robustness of the estimates obtained. The empirical results confirm the relevance of technology demonstration fields, farmers' experience, training, and sex (gender) in enhancing and sustaining the adoption of improved agricultural technologies among rice farmers. Household extension method, research and extension, and farm size should also be considered in promoting the adoption of improved practices among rice farmers since these covariates had significant relationships with the intensity of adopting improved rice production technologies.

\section{REFERENCES}

ABDUL-HANAN, A., AYAMGA, M. and DONKOH, S. A. (2014). Smallholder adoption of soil and water conservation techniques in Ghana. African Journal of Agricultural Research. 9(5), 539-546. DOI: 10.5897/AJAR2013.7952

ADESINA, A. A. and BAIDU-FORSON, J. (1995). Farmers' perceptions and adoption of new agricultural technology: evidence from analysis in Burkina Faso and Guinea, West Africa. Agricultural economics, 13(1), 1-9. https://EconPapers.repec.org/RePEc:eee:agecon:v:13:y:1 995:i:1:p:1-9

ANANDAJAYASEKERAM, P., PUSKUR, R., SINDU W. and HOEKSTRA, D. (2008). Concepts and practices in agricultural extension in developing countries: A source book. IFPRI (International Food Policy Research Institute), Washington, DC, USA, and ILRI (International Livestock Research Institute), Nairobi, Kenya. https://cgspace.cgiar.org/bitstream/handle/10568/99/Sour ce book.pdf

ANGELUCCI, F., ASANTE-POKU, A. and ANAADUMBA, P. (2013). Analysis of incentives and disincentives for rice in Ghana. Technical notes series, MAFAP, FAO, Rome. www.fao.org/3/a-at546e.pdf AZUMAH, S. B., DONKOH, S. A. and ANSAH, I. G. K. (2017). Contract farming and the adoption of climate change coping and adaptation strategies in the northern region of Ghana. Environment, Development and Sustainability, 1-21. DOI: https://doi.org/10.1007/s10668-016-9854-Z

AZUMAH, S. B., TINDJINA, I., OBANYI, S. and WOOD, T. N. (2017). Productivity Effect of Urea Deep Placement Technology: An Empirical Analysis from Irrigation Rice Farmers in the Northern Region of Ghana. World Academy of Science, Engineering and Technology, International Journal of Biological, Biomolecular, Agricultural, Food and Biotechnological Engineering, 11(3), 194-199.

https://pdfs.semanticscholar.org/3e38/ee5114a071ebeb60 eb0b30d8564427129baf.pdf

BÖHNING, D., DIETZ, E., SCHLATTMANN, P., MENDONCA, L. and KIRCHNER, U. (1999). The zeroinflated Poisson model and the decayed, missing and filled teeth index in dental epidemiology. Journal of the Royal Statistical Society, Series A (Statistics in Society). Wiley Online Library. 162 (2): 195-209. DOI: 10.1111/1467985X.00130

CAMERON, A.C. and TRIVEDI, P.K. (2010). Microeconometrics Using Stata: Stata Press.

DANSO-ABBEAM, G., and BAIYEGUNHI, L. J. (2017). Adoption of agrochemical management practices among smallholder cocoa farmers in Ghana. African Journal of Science, Technology, Innovation and Development, 1-12. DOI: $10.1080 / 20421338.2017 .1380358$

DANSO-ABBEAM, G., SETSOAFIA, D. E. and ANSAH. I. G. K. (2014). Modelling Farmers Investment in Agrochemicals: The Experience of Smallholder Cocoa Farmers in Ghana. Research in Applied Economics, 6(4), 12-27. DOI: https://doi.org/10.5296/rae.v6i4.5977 dEGRAFT-JOHNSON M., SUZUKI, A., TAKESHI SAKURAI, T. and OTSUKA. K. (2014). On the transferability of the Asian rice green revolution to rain fed areas in sub-Saharan Africa: An assessment of technology intervention in Northern Ghana. Agricultural Economics, $\quad 45, \quad 555-70 . \quad$ DOI: https://doi.org/10.1111/agec.12106

DONKOH, S. A. and AWUNI, J. A. (2011). Adoption of farm management practices in lowland rice production in northern Ghana. Global Research Journal, 2(6), 189-191. FOOD AND AGRICULTURE ORGANISATION (FAO) (2013). Success Stories on Climate-Smart Agriculture. FAO Climate-Smart Agriculture (CSA) Sourcebook 2013. Www.fao.org/climatechange/climatesmart/en/

FOOD AND AGRICULTURE ORGANIZATION OF THE UNITED NATIONS (FAO) (2011). The State of Food and Agriculture 2010-2011 - Women in Agriculture: Closing the Gender Gap for Development. 
FAO; $\quad$ Rome, Italy: www.fao.org/docrep/013/i2050e/i2050e.pdf

GHANA STATISTICAL SERVICE (GSS, 2012). Population and Housing Census, 2010. Ghana. www.statsghana.gov.gh

GHANA STATISTICAL SERVICE (GSS, 2014). Ghana Living Standard Survey Round 6. Poverty Profile in Ghana (2005-2013). http://www.statsghana.gov.gh

GHANA STATISTICAL SERVICE (GSS, 2014). National Accounts Statistics. Final 2012 Gross Domestic Product \& Revised 2013 Gross Domestic Product. www.statsghana.gov.gh

ISGIN, T., BILGIC, A., FORSTER, D. L. and BATTE, M. T. (2008). Using count data models to determine the factors affecting farmers' quantity decisions of precision farming technology adoption. Computers and Electronics in Agriculture, 62, 231-242. DOI: https://doi.org/10.1016/j.compag.2008.01.004

JOHNSON, N. L., KOTZ, S. and KEMP, A. W. (1992). Univariate Discrete Distributions (2nd Ed.). Wiley. 312314.

LAMBERT, D. (1992). Zero-Inflated Poisson Regression, with an Application to Defects in Manufacturing. Technometrics. 34 (1), 1-14. DOI: 10.2307/1269547

LOHR, L. and PARK, T. A. (2002). Choice of insect management portfolios by organic farmers: Lessons and comparative analysis. Ecological Economics, 43: 87-99. DOI: https://doi.org/10.1016/S0921-8009(02)00184-2 MENSAH-BONSU, A., SARPONG, D. B., ALHASSAN, R., ASUMING-BREMPONG, S., EGYIR, I. S., KUWORNU, J. K., and OSEI-ASARE, Y. B. (2017). Intensity of and factors affecting land and water management practices among smallholder maize farmers in Ghana. African Journal of Agricultural and Resource Economics, 12(2), 142-157.

MINISTRY OF FOOD AND AGRICULTURE (MoFA) (2013). Agriculture in Ghana: Facts and Figures (2012). Statistics, Research and Information Directorate (SRID) (pp. 1-45). Accra. www.mofa.gov.gh

MINISTRY OF FOOD AND AGRICULTURE (MoFA) (2016). Agriculture in Ghana. Facts and Figures 2015. Statistics, Research and Information Directorate (SRID) of MoFA, October 2016. www.mofa.gov.gh
NDPC (2005). Growth and poverty reduction strategy (GPRS II): 2006 - 2009. National Development Planning Commission, Accra, Republic of Ghana. www.ndpc.gov.gh

NDPC (2010). Implementation of the growth and poverty reduction strategy, 2009: Annual Progress Report. Development Planning Commission, Accra, Republic of Ghana. www.ndpc.gov.gh

NKEGBE, P. and SHANKAR, B. (2014). Adoption intensity of soil and water conservation practices by smallholders: evidence from Northern Ghana. Bio-based and Applied Economics, 3(2), 159-174. DOI: 10.13128/BAE-13246

RAGASA, C., DANKYI, A., ACHEAMPONG, P., NIMO WIREDU, A., CHAPOTO A., ASAMOAH, M. and TRIPP, R. (2013). Patterns of Adoption of Improved Rice Technologies in Ghana. GSSP-IPFRI. Working Paper 35, July 2013.

SHARMA, A., BAILEY, A. and FRASER, I. (2011). Technology adoption and pest control strategies among UK cereal farmers: Evidence from parametric and nonparametric count data models. Journal of Agricultural Economics, 62(1), 73-93. DOI: $\underline{10.1111 / \mathrm{j} .1477-}$ 9552.2010.00272.x

UNITED NATIONS FRAMEWORK CONVENTION ON CLIMATE CHANGE (UNFCCC) (2007). Climate change: impacts, vulnerabilities and adaptation in developing countries. (Available at http://unfccc.int/resource/docs/publications/impacts.pdf UZONNA, U. R. and QIJIE, G. (2013). Effect of extension programs on adoption of improved farm practices by farmers in Adana, southern Turkey. Journal of Biology, Agriculture and Healthcare, 3, 17-23.

WANG, L., HUO, X. and KABIR, M.S. (2013): Technical and cost efficiency of rural household apple production. China Agricultural Economic Review, 5(3), p. 391-411. DOI: 10.1108/CAER-08-2011-0087. 